\title{
DE CÓMO EL ROMAN FUSION LLEGÓ A SERLO: PREHISTORIA LITERARIA DE UNA NUEVA FÓRMULA NARRATIVA
}

\author{
Joaquín JUAN PENALVA \\ Universidad de Alicante
}

La literatura reciente es como el puntillismo, pues sólo con la distancia abandona el territorio de lo abstracto y se percibe como un arte figurativa, en que los perfiles acaban sometidos a los dictados de un juez estricto, severo y no siempre sabio: el tiempo. Los autores son conscientes de ello, y algunos tratan de conjurar un más que probable olvido esgrimiendo cifras de ventas escandalosamente rentables; otros, por el contrario, tienen a gala los desastres comerciales de sus aventuras literarias y cifran todas sus esperanzas en una justicia - ¿ciega?, ¿poética?- que los eleve a un particular parnaso: el temible canon. Los críticos que se internan en estos territorios inexplorados suelen hacerlo a tientas, abriendo sendas que serán más o menos transitadas en función de lo que depare la historia literaria, que, con frecuencia, es caprichosa y tiende, sobre todo a partir del siglo XX, a mostrarse benevolente con quienes han tomado la precaución de manufacturar o hacerse construir un caparazón teórico-estético bajo el que cobijar sus obras. De ahí que los críticos hayan practicado con frecuencia sobre unos -autores-y otras -obras- esmerados ejercicios de clasificación, taxonomía, análisis, y, en ocasiones, disección e incluso momificación, lo que ha dado como resultado un amplio abanico de marbetes, etiquetas, nomenclaturas y otras denominaciones más o menos nocivas para el continuum de la literatura.

Desde hace un par de años, a ese nada exclusivo club podemos sumar otro miembro, lo que se ha venido llamando roman fusion o «novela fusión», concepto de nueva planta. aue. sin embargo. no hace más aue radicalizar una tendencia 
- de hibridación entre las distintas artes y de mestizaje entre los distintos géneros- presente en el panorama literario español desde hace tiempo, y especialmente cultivada en la novelística del último cuarto del siglo XX. No sé si también el importador, pero el más destacado publicista de esta nueva fórmula ha sido José «Pote» Huerta, director editorial de Lengua de Trapo; asimismo, son dos de los escritores de su catálogo los que han flirteado de manera más indiscreta con esta técnica de subversión narrativa: Rafael Reigl y Elia Barceló ${ }^{2}$. Sus novelas y sus lecturas ocuparán las siguientes páginas, donde trataré de definir la novela fusión española y de apuntar precedentes en autores como Gonzalo Torrente Ballester, Francisco García Pavón o Eduardo Mendoza, entre otros.

Independientemente de lo que pueda haber de carga comercial en esta etiqueta, lo cierto es que el roman fusion ha abierto nuevos caminos para el género novelístico dentro y fuera de España, y eso se debe fundamentalmente a que, según afirma Huerta, «es una especie de recombinación genética del ADN de diferentes formatos narrativos, desde la serie negra clásica a la ciencia-ficción, incluyendo la novela picaresca o el folletín decimonónico, por ejemplo, y siempre para crear algo diferente que supone a la vez una «revisitación» de la tradición literaria y una renovación de sus posibilidades»; de ahí que asimismo se haya denominado en ocasiones novela transgénica, esto es, en la que se introducen uno o varios genes de otra especie narrativa, lo que equivaldría a decir novela transgenérica, ya que no se circunscribe a un único género, sino que visita varios de ellos -sobre

1 Rafael Reig (Cangas de Onís, Asturias, 1963) es licenciado en Filosofia y Letras por la Universidad Autónoma de Madrid -la misma que retrata en su primera novela, Esa oscura gente- y doctor por la State University of New York at Stony Brook con una tesis sobre las prostitutas en la novela del siglo XIX: Mujeres por entregas: la prostituta en la novela del XIX. Sus dos primeras novelas, Esa oscura gente (1990) y Marilyn. Autobiografia apócrifa (1992), no han gozado de tanta difusión como las últimas, La formula Omega. Una de pensar (1998), Sangre a borbotones (2002) y Guapa de cara (2004). De todas maneras, no creo que deba trazarse una separación tajante entre el primer tramo creativo y el segundo, pues cada novela supone un ejercicio de madurez, desarrollo y perfeccionamiento de la anterior. Reig, además, ha compatibilizado sus múltiples tareas profesionales con la de editor, lo que le ha servido para rescatar del purgatorio de las publicaciones periódicas algunas piezas muy interesantes, que, junto a sus novelas, conforman un particular universo dificilmente intercambiable.

2 Elia Barceló (Elda, Alicante, 1957) es licenciada en Filología Anglogermánicá por la Universidad de Valencia y en Filologia Hispánica por la de Alicante, y doctora en Literatura Hispánica por la Universidad de Innsbruck, donde es profesora. En 1991 recibió el Premio Ignotus por su relato «La Estrella», y El mundo de Yarek (1993) fue merecedora del Premio Internacional UPC de novela corta de ciencia-ficción. A este mismo género pertenecen sus novelas Sagrada (1989) y Consecuencias naturales (1994). También ha publicado algunos titulos destinados al público juvenil: El caso del artista cruel (1997), La mano de Fatma (2001), El almacén de las palabras terribles (2003), El caso del crimen de la ópera (2003), Si un dia vuelves a Brasil (2003) y La roca de Is (2003). Sus últimas novelas no juveniles son El vuelo del Hipogrifo (2002), El secreto del orfebre (2003), El contrincante (2004) y Disfiaces terribles (2004). 
todo los más codificados-. También se ha empleado el término sajón slipstream, que alude al flujo de aire o estela que deja tras de sí un objeto que se mueve muy rápido, habitualmente un coche o un avión, e incluso algunos han aventurado un neologismo como novelibrida, que, entre burlas y veras, pretende dar cuenta del carácter trasgresor y subversivo -por lo menos desde la perspectiva narrativa, no necesariamente desde el punto de visto ideológico- de esta novelística.

Los cultivadores del roman fusion recuperan los fines estético, lúdico y metaliterario de la escritura, la idea de la literatura como juego, en un proceso que supone, en palabras del responsable de Lengua de Trapo, «una profunda revisión del canon de la que surge una concepción nueva del género: ruptura de moldes e hibridación, recuperación de la comunicación con el lector y del planteamiento moral, e instauración de nuevo en el "principio del placer", fuera del reino de la necesidad... de parecer culto o serio». Todo esto viene acompañado por una idea de relevo generacional, pues los nuevos autores son los primeros que han crecido viendo la televisión y los que han asistido de manera privilegiada al desarrollo de la informática y de las telecomunicaciones, un terreno en el que la realidad tecnológica ha sobrepasado con creces a la ciencia-ficción clásica. El cine, que se ha ido interrelacionando con la literatura a lo largo de más de una centuria, es elevado en las obras de Reig y Barceló a fuente directa de inspiración, lugar que comparte también con ciertas manifestaciones marginales de la cultura, como la novela rosa, pornográfica, del oeste...

En estos últimos años hemos asistido a una dura pugna entre la cultura escrita -predominante hasta ahora-y la visual. Aunque todavía prevalece el prestigio de lo escrito, la pujanza de lo visual se ha acelerado considerablemente gracias al desarrollo espectacular de la tecnología. Estos autores, nacidos en las décadas del cincuenta y del sesenta, se hicieron adultos cuando todavía no había internet, móviles, ordenadores personales, consolas..., pero han alcanzado la madurez en un mundo distinto, en el que la imagen lo ocupa todo. Son, en ese sentido, escritores de transición, un fin de raza, pues las nuevas promociones -sus hermanos pequeños, sus sobrinos, sus hijos...- han venido al mundo con un joystick o un gamepad bajo el brazo.

El nuestro es un tiempo de reconfiguración, no sólo estética o literaria, y la novela fusión, en cierto modo, implica una nueva cosmovisión. Lo que hay, de hecho, es una recombinación de elementos ya existentes, e incluso empleados en ocasiones por novelistas de promociones anteriores. Según Elia Barceló, el roman fusion es «por una parte, una declaración de amor a la literatura, y por otra un intento de buscar nuevos caminos adecuados a nuestro tiempo, a una sociedad -hablo de la occidental- más rápida, más lúdica, más tolerante y relativizadora» (Ex Libris, 2004: 90-91). No se trata, por tanto, de un nuevo género, sino de la relectura de los géneros preexistentes, como ya se ha dicho. Elia Barceló se 
remonta a los inicios de la literatura romance para buscar las raíces de la fusión: «El Libro de Buen Amor no es una novela, pero ya es una fusión; La Celestina está a caballo entre el teatro y la novela; y la mayor de nuestras novelas, Don Quijote de la Mancha, usa todas las tradiciones narrativas de su época, incluyendo historias de otros géneros dentro de la historia principal, empleando ya lo lúdico como hilo conductor de la narración» (Ex Libris, 2004: 91).

A causa de las características peculiares del roman fusion, heterogéneo y proteico por naturaleza, no hay una receta unívoca a la hora de cocinar todos esos ingredientes de procedencia diversa, y la disposición última de los mismos queda al arbitrio del escritor, que puede combinarlos a su sabor. Tanto Rafael Reig como Elia Barceló son excelentes fogoneros, de ahí que cada uno de sus platos tenga un toque especial que lo convierte en único e irremplazable. Un corpus mínimo y esencial del roman fusion habria de incluir necesariamente cuatro novelas, todas ellas publicadas en Lengua de Trapo: La fórmula Omega. Una de pensar (1998) y Sangre a borbotones (2002), de Rafael Reig; y El vuelo del Hipogrifo (2002) y El secreto del orfebre (2003), de Elia Barceló. Si efectivamente se trata de una nueva forma de entender la novela, debe haber muchos más títulos que quepan dentro de esa idea de mestizaje. No obstante, para nuestros intereses, que pasan por rastrear los precedentes del roman fusion en la novelística española del último cuarto de siglo, bastará con esta tetralogía, pues desde esas cuatro novelas se apuntan muchos de los temas dilectos, las técnicas favoritas y las artes privilegiadas-cine y literatura, fundamentalmente-.

A la hora de aproximarse a la labor narrativa de Rafael Reig, puede resultar interesante tener en cuenta su oficio de arqueólogo literario, desempeñado en la colección de «Rescatados» de Lengua de Trapo. Como editor literario, el asturiano ha tenido a su cargo Las virgenes locas (1999), una novela colectiva publicada por entregas en el Madrid Cómico entre mayo y septiembre de 1886, en la que, entre otros autores, intervenía Clarin ${ }^{3}$, y El crimen de la calle Fuencarral. El

${ }^{3}$ Ocasionalmente, los escritores sienten una irrefrenable tentación de probarse a sí mismos como tales, poniéndose cuantas trabas, obstáculos y pies forzados sean necesarios para lograr un tripe salto mortal sin red de orden literario, o, en palabras de Rafael Reig, el encargado de la edición mencionada, «una huida hacia delante basada en el principio narrativo-circense del más dificil todavía) (AA. VV., 1999: XVIII). El resultado literario -normalmente de escaso valor- no es tan relevante como los subterfugios de que se vale cada autor para salir del brete en que le ha metido su predecesor. Todo esto está presente en Las vírgenes locas, cuyos responsables se afanaron en crear una de las obras más particulares, atractivas y extravagantes de cuantas pudieron disfrutar los lectores de su tiempo. Las virgenes locas es una auténtica joya literaria del siglo XIX, no sólo por lo interesante del proyecto, sino porque pone al descubierto la técnica y los trucos empleados por los novelistas. Es, al mismo tiempo que homenaje, burla de las novelas góticas y filosóficas, pero también de las de misterio y amor. Sus autores revelan muchos trucos del oficio, permitiendo que el lector contemple la tramoya literaria que se esconde tras los argumentos y los diálogos. 
crimen del cura Galeote (2002), una selección de las crónicas que Benito Pérez Galdós enviaba al diario argentino La Prensa. En sus reflexiones sobre esos «textos rescatados» hay mucho de su propia concepción de la novela. He aquí, por ejemplo, los ingredientes de cuya combinación resulta ese explosivo cóctel de Las vírgenes locas: «Hay parodia del folletín, con "personajes salvados milagrosamente por unos rusos" y también de la narración gótica (asesinos en serie, noches lúgubres, mensajes secretos a lo Hoffman o Poe). / Hay el distanciamiento que las distingue de esas propuestas que siempre se toman a sí mismas demasiado en serio: "La noche era oscura, según es costumbre en estos casos"》 (AA. VV., 1999: XII). Todas estas características podrían aplicarse sin violencia a la novelística de Reig, que ha encontrado en estos «textos perdidos» magníficos modelos. Tanto o más interesantes son sus afirmaciones sobre el género criminal a propósito de las crónicas de Galdós:

Hoy en día, cuando la literatura criminal parece haber descrito un círculo (probablemente vicioso), resulta refrescante esta miniatura galdosiana en la que Higinia mata por catorce mil duros, con un cuchillo de cocina y ayudada por su «compinche». En estos tiempos de asesinos psicópatas, a lo Hannibal Lecter, que matan por las más enrevesadas razones psicológicas; o bien ahijados de Fu Manchú, que conspiran en la sombra y utilizan, pongamos, aceleradores de partículas ionizadas o cepas de virus experimentales inyectadas con jeringuilla, resulta bastante saludable reencontrarse con criminales que no oyen voces interiores ni pretenden el control absoluto del planeta, que no tienen un cociente intelectual extraordinario ni habilidades circenses y tecnologías vanguardistas: vecinos de enfrente, seres humanos como la Higinia de Galdós, que había vivido «maritalmente con un lisiado», mataba por codicia rudimentaria y era «un monstruo de astucia y marrullería». Es Dashiell Hammett en versión Chamberí (Reig; en Pérez Galdós, 2002: XVI-XVII).

Según las afirmaciones de Reig, ronda por su escritura una idea que resulta fundamental a la hora de abordar Sangre a borbotones en particular y toda su novelística en general. Se trata de la mezcla e hibridación de géneros narrativos, la parodia de ciertos esquemas y el injerto de elementos de procedencia diversa. Esto nos lleva a formular una receta novelística difícil de precisar, pero con algunos ingredientes imprescindibles que no pueden faltar en la cocina del escritor: un poco de folletín; un trasfondo de ciencia-ficción; algo de bildungsroman o novela de aprendizaje, a ser posible en su variante de künstlerroman o novela de artista; mucho de novela negra y cine policíaco; una pizca de novela rosa; un pellizco de relato pornográfico, novela del oeste y cuento filosófico; y, por último, todo ello debidamente salpimentado, sazonado y espolvoreado con las oportunas dosis de humor, ironía, sarcasmo y, por supuesto, metaliteratura. 
En realidad, bajo la apariencia de novedad y subversión, lo que encontramos no es una neovanguardia, sino una revisión de la tradición literaria. Reig apunta, y con razón, a Cervantes, quien «mezclaba novela de caballerías, pastoril, personajes que salen de los libros y van a la realidad...». Ésta es, efectivamente, una de las características fundamentales de la producción del asturiano, que asume toda esa literatura y después la despliega de manera más o menos explícita en sus novelas, según sus propias afirmaciones: «la literatura es un proceso digestivo: el autor tiene que comer de todo, en la vida y en los libros, y luego devolverlo convertido en algo nuevo, a ser posible nutritivo».

La fórmula Omega. Una de pensar, la tercera novela de Rafael Reig, es algo anterior a las otras tres que conforman nuestro corpus mínimo, pues se publicó en 1998; sin embargo, no se trata de un roman fusion en agraz y avant la lettre, sino de una novela fusión en sentido estricto, que comparte más elementos con Sangre a borbotones que con Esa oscura gente y Marilyn. Autobiografía apócrifa, las dos primeras novelas del autor. La fórmula Omega se divide en treinta y siete capítulos de extensión breve, todos ellos con título, a los que precede una «Carta de ajuste» y a los que sigue una «Despedida y cierre». Hay dos tramas, la que acontece en el plano real -en Madrid, escenario imprescindible de la novelística de Reig-, y la que tiene lugar en el mundo televisivo de Venezolandia, donde había estallado una guerra fratricida «en el capítulo 375 de Inverecunda Fernández, cuando la Reina de la Pequeña Pantalla, Zenaida Madurka, iba a llamar por teléfono a Julio Alberto Bustamante, el popular capitán de empresa» (Reig, 1998: 21). Conforme avanza la novela, las dos tramas confluyen y los personajes de la pequeña pantalla se pasean por el mundo sensible, tal como ocurría en La rosa púrpura de El Cairo. Reig parte de una brillante premisa argumental que le permite situar la historia en un tiempo y lugar concretos:

Norte de Madrid, comienzos de los noventa. Los trenes de cercanías efectúan parada en todas las estaciones excepto Pitis. [...] En el subsuelo pítico, a trescientos sesenta metros de profundidad bajo el nivel medio del mar en Alicante, se encuentra un búnker excavado en roca viva (granito plutónico del Guadarrama). Se trata de uno de los cinco lugares del planeta protegidos por un Perimetro de Seguridad Total (PST).

En ellos se reúne el Directorio Secreto (DS): los doce hombres que gobiernan el mundo en la sombra; los que de verdad mueven los hilos (Reig, 1998: 11).

El personaje que hilvana todos los episodios es Antonio Maroto, un antiguo niño prodigio del ajedrez que ahora «conducía un taxi, componía problemas de mate en tres y había organizado el Comando Suicida del Club Gambito» (Reig, 1998: 15). Al tiempo que se desarrolla la acción, asistimos a numerosos flashbacks de Maroto, que recuerda sus años de infancia y adolescencia, en los que se fraguó 
la prehistoria de un fracaso, especialmente acentuado durante su estancia en París, adonde llegó «demasiado tarde: todos acababan de irse a Nueva York hacía cinco minutos» (Reig, 1998: 24).

En el capítulo 12, «La invasión de la realidad», uno de los más logrados de toda la novela, Reig traza unos paralelismos asombrosos y desconcertantes entre la historia del ajedrez y la universal. Tanto el Renacimiento como el socialismo o el capitalismo tienen su equivalente en el mundo del escaque, que se puede plantear como una lucha eterna entre el Bien y el Mal:

El apacible Lasker había sido un compás de espera que precedió al primer artista moderno, el Ángel Custodio, José Raúl Capablanca, la «máquina de jugar al ajedrez», el cubano invencible, el hombre que abrió de par en par las puertas a la expansión económica mundial y a la edad del jazz. [...] Precisamente en el juego de Capa lo había aprendido todo el Renegado, el perverso aristócrata Alexánder Alexandróvich Alekhine, el Ángel de la Muerte.

-La sombra de su vuelo nublaba continentes, camaradas.

Con Alekhine el juego perdió la inocencia y lo que hasta entonces ni siquiera parecía concebible se hizo realidad: Adolfo Hitler, las cámaras de gas, los experimentos genéticos, la destrucción de los átomos... (Reig, 1998: 61-63).

Reig suele homenajear en sus obras a los autores que le han servido de aliento o de modelo. En La fórmula Omega, uno de los capítulos se titula «Le dernier métro», como la película de Truffaut, y en la descripción de un personaje, «mujer con alcuza», emerge el título de un poema de Dámaso Alonso. Algo parecido ocurre en las páginas finales cuando el narrador afirma que «era el comienzo de una hermosa amistad» (Reig, 1998: 181).

Hay muchas similitudes entre La fórmula Omega y la penúltima novela publicada por Reig hasta la fecha ${ }^{4}$, Sangre a borbotones, aparecida en los primeros meses de 2002. En ella se produce una nueva radicalización del mestizaje de géneros narrativos -en esta ocasión, casi llevado al extremo, pues el autor flirtea con el relato pornográfico y la novela del oeste, absolutamente desprestigiados en los ámbitos académico e intelectual-. Sangre a borbotones viene precedida por sendas citas de Claudio Rodríguez y Joao Guimaraes Rosa, está narrada en primera persona y consta de cuarenta capítulos breves sin título ni número.

Toda la obra se sustenta sobre un falso supuesto, un «¿qué habría ocurrido si...?», pero los detalles de esa proyección se van administrando en pequeñas

${ }^{4}$ La última, Guapa de cara (2004), rescata el Madrid distópico y veneciano de Sangre a borbotones, pero traiciona el espíritu de la novela anterior mediante un proceso de sobreabundancia y esperpentización desmesurada. Hay en estas novelas mucho de pastiche y de collage, de ahí que resulte fundamental medir las dosis para no incurrir en un excesivo recargamiento. 
dosis. Así, por ejemplo, Clot, al recordar a su padre, afirma lo siguiente: «Antes debía de querer decir antes de que muriera Franco y de que el Partido Comunista ganara las elecciones, antes de la invasión y de que se acabara el petróleo, antes del anglo obligatorio y de las alteraciones genéticas, de que inundaran la Castellana para construir el canal y de que mi padre se quedara ciego») (Reig, 2002: 20). Más adelante, intenta imaginarse un Madrid alternativo, otra realidad posible si no se hubiera dado dicho supuesto, lo que produce cierto regusto amargo, pues está describiendo la realidad existente fuera de la novela:

Tal vez en un mundo paralelo, el de lo que podría haber sido y no fue, un mundo en el que el Partido Comunista no hubiera ganado las elecciones y entonces Estados Unidos no habría invadido la península ibérica. Un mundo en el que no se hubiera acabado el petróleo ni se hubiese descifrado el genoma. Una vida diferente, con automóviles y monarquía constitucional, sin modificaciones genéticas ni leyes que las hicieran obligatorias. ¿Seríamos más o menos felices? No lo sé, a lo mejor también había atascos, igual que con las bicis, y castigos para los yonquis y los padres de discapacitados. A lo mejor también hablábamos en anglo (Reig, 2002: 98-99).

Ciertos componentes del texto, como la posibilidad de un presente y un futuro alternativos a partir de un pasado distinto pero factible, acaban por aproximar Sangre a borbotones al género de la distopia, que tiene sus mayores modelos en títulos como Un mundo feliz (1932), de Aldous Huxley, 1984 (1949), de George Orwell, y La naranja mecánica (1962), de Anthony Burgess, entre otros muchos.

Las alusiones literarias y cinematográficas son muy abundantes a lo largo de todo el texto. En ocasiones, la alusión es directa, como ocurre en el caso de Hamlet, El resplandor, El sueño eterno, Con faldas y a lo loco... Otras veces, en cambio, para llegar al reconocimiento se ha de partir de cierta complicidad, como cuando se reproducen las primeras frases de Cien años de soledad: «Habian pasado muchos años y, como si estuviera frente al pelotón de fusilamiento, me puse a recordar la primera vez que mi padre me llevó a conocer el hielo» (Reig, 2002: 19). Esta misma técnica la emplea también para rendir un homenaje velado a Ray Bradbury y François Truffaut, por un lado -«En el centro de la imagen había unos puntos rojos que, por su color intenso, debían de haber alcanzado una temperatura muy alta: Farenheit 451» (Reig, 2002: 35)-, y a Rafael Sánchez Ferlosio, por otro - Unn mes más tarde fui a su entierro. Desde una goleta con las velas teñidas de negro aventamos sus cenizas en el río Jarama, en el mismo remanso donde íbamos a nadar con quince años. Según contaban, allí se ahogó una chica en los años cincuenta, un accidente que dio mucho que hablar» (Reig, 2002: 105)-.

De todas maneras, esto supone sólo una pequeñísima muestra de lo que podemos encontrar en Sangre a borbotones, pues Reig es muy dado a este tipo de juegos intertextuales, y en todas sus novelas hay un buen número de guiños 
y homenajes, cuando no citas casi literales, de sus autores y películas favoritos. Aparece también en esta novela una referencia tanto a la editorial en que se ha publicado - «Son regalos de mis lectores -me comentó con acrimonia y lengua de trapo (Reig, 2002: 45)»-como al editor de la misma -«Es don Lewis H. Visiedo, el segundo ejecutivo de Telefónica, tiene el cargo de vicepresidente, justo por debajo del C.E.O., don Javier Azpeitia, y con un puesto permanente en el Consejo» (Reig, 2002: 73)-.

Su obra no bebe directamente de la realidad, sino que en ella todo queda tamizado por la literatura y el arte. Se produce, pues, un ejercicio de sublimación, en el que todo está montado sobre algo preexistente, ya sean novelas, películas o poemas. Tampoco se trata de un ejercicio de culturalismo, sino de desmitificación de los grandes modelos, haciendo coincidir en un mismo espacio narrativo a héroes extraídos de las novelas de Marcial Lafuente Estefanía con autores consagrados. La realidad, en este sentido, sólo importa cuando llega a través del arte. Así, el Madrid que se nos presenta no es un lugar geográfico concreto, sino una creación literaria que bebe sobre todo de la literatura. Se trata, en definitiva, de un ejercicio de estilo, de una pirueta. No es una huida de la realidad, sino una apropiación de la misma a través del filtro de lo artístico, lo que transporta al lector a un mundo en el que coinciden un Madrid inundado y un bar de chatos, una gran multinacional y una antigua Orbea, el protagonista de una novela del oeste y un detective triste de bajos vuelos.

El inicio de la novela bebe directamente del género policíaco: Carlos Clot, un detective de oscuro pasado y futuro incierto acaba de aceptar el encargo de encontrar a una adolescente, Lovaina Leontieff. Sin embargo, pronto descubrimos que hay algunos elementos que no encajan con el esquema tradicional de la novela negra: «Los dos sabíamos que, fuera de un Precinto, las autoridades no tardarían en localizarla y entonces la neutralizarían genéticamente en los laboratorios de Chopeitia. Es la ley» (Reig, 2002: 11). Enseguida será el propio Clot el que saque al lector de dudas, ya que se refiere a un Madrid futuro -o, por lo menos, alternativo- en que la Castellana es un canal transitado por barcos y, a falta de petróleo, los ciudadanos se desplazan en bicicleta. Lo que ha ocurrido es que el género policíaco se ha mezclado con la ciencia-ficción, tal como ocurría en Blade Runner (1982), película de Ridley Scott que se basaba, a su vez, en ¿Sueñan los androides con ovejas eléctricas?, de Philip K. Dick. Así, por ejemplo, el piso de Clot recuerda en muchos aspectos al de Deckard, el cazador de replicantes: «Era asqueroso, sí, es verdad, pero el alquiler resultaba muy barato y yo no tengo manías. El casero tuvo que rebajarlo porque el anterior inquilino, Carlos Viloria, había tenido la ocurrencia de suicidarse in situ y luego los demás artistas-escritores no querían ocupar la vivienda. Son así de sensibles. Cuando llegué aún estaba la silueta de su cuerpo dibujada con tiza en el suelo» (Reig, 2002: 18). 
Como suele ser habitual en este tipo de relatos, la historia personal del detective circula de manera paralela a los casos que ha de resolver, hasta que, en un determinado momento, ambas tramas confluyen. Desde el comienzo percibimos que Clot es un fracasado, pero las dimensiones de su fracaso sólo se irán perfilando a medida que transcurra la acción: «a mi edad, de casi todo hacía ya veinte años» (Reig, 2002: 56), afirma en una ocasión.

El protagonista es requerido para dos casos más: el primero, aparentemente rutinario, consiste en confirmar la presunta infidelidad de la esposa de Alfred $\mathbf{J}$. Carvajal; el segundo, en cambio, es de cariz metaliterario, pues se trata de encontrar a un personaje fugado de la última obra de Phil Sparks, pseudónimo de Luis María Peñuelas, autor de novelas del oeste de las que se venden en los quioscos. El nombre del personaje: Mabel Martínez; el título de la novela: Sangre a borbotones.

También el ajedrez está presente en esta obra, así como una tertulia literaria en la que se reúnen los famosos «gepuntos», críticos especializados que nunca daban a conocer su primer apellido, sino que lo escondían tras una inicial seguida de un punto. Al empezar a buscar a Mabel Martínez, Clot pronto se tropieza con Manex Chopeitia, el Presidente de Chopeitia Genomics, un ser legendario y luciferino, cuya lugarteniente, Dee Dee Reeves, apodada la Despiadada, era «una mujer de dos metros de altura que iba siempre con la ropa interior por fuera» (Reig, 2002: 52). Sus investigaciones pronto le conducen hacia el famoso Protocolo 47, que probaba la financiación por parte de Telefónica de algunos experimentos ilegales de Chopeitia Genomics. Pronto, sin embargo, dos de sus desaparecidas se convierten en cadáveres, la señora Carvajal y la joven Lovaina. A partir de ese momento, la vida privada de Clot, que tiene ciertas similitudes con la del propio Reig, cobra importancia en la trama.

La obra de Reig bascula entre unos extremos perfectamente reconocibles y entre unas fórmulas a las que el autor recurre una y otra vez, conformando un universo narrativo propio en cuyas páginas el lector atento descubrirá un buen número de citas, homenajes y guiños de Reig tanto a su propia obra como a la de sus escritores más admirados. Al tiempo que un ejercicio de creación, su producción literaria es una recreación constante de todos los libros que ha leído y a todas las películas que ha visto; no tanto un ejercicio intelectual como la plasmación de una memoria cultural.

Si comparamos las novelas de Reig con las de Elia Barceló, a quien se ha considerado la «Gran Dama española de la ciencia-ficción», descubriremos algunas diferencias notables en el modo de preparar el roman fusion. Hay en la autora alicantina un prurito de pureza estética que la lleva a tomarse esta nueva fórmula muy en serio y a no caer en la desmitificación, al menos en sus dos últimas novelas, ya que sí había parodia en Consecuencias naturales (1994), una novela de 
ciencia-ficción sobre relaciones sexuales de carácter extraterrestre, con embarazo masculino incluido.

Elia Barceló ha empleado los conceptos de «novela interactiva» y "parque temático» para referirse a la que, hoy por hoy, es su obra más ambiciosa, El vuelo del Hipogrifo, cuya historia podría transformarse en un excelente guión para una aventura gráfica, ya que asistimos al viaje de iniciación de Katia Steiner en busca de su propia identidad a través de mundos reales, ficticios y literarios. La propia autora se ha referido a su novela en estos términos: «El vuelo del Hipogrifo es una novela fusión en la que, por medio de diferentes tradiciones narrativas (género policíaco, fantástico, épica culta, novela pastoril, folletín, etc.) se narra una historia llena de secretos por desvelar y misterios que resolver, con un ritmo rápido, personajes contemporáneos y creibles y ambientada en diferentes lugares, unos existentes, otros no tanto». La novela transcurre entre Roma, Innsbruck, Alma - una isla de de la costa de Umbría, invención de la autora-y una serie de mundos pictórico-literarios a los que los personajes acceden a través de portales dimensionales. El vuelo del Hipogrifo despliega una amplia gama de recursos, fundamentalmente de estirpe literaria, y es, por lo menos hasta la fecha, la novela fusión de mayor empaque y aliento. Es una obra compleja en la que se superponen diversos niveles narrativos -uso de la primera y tercera personas, diarios, cartas...-, dando como resultado una novela única construida a partir de la adición de diferentes relatos. Según la autora, esta obra «es la novela que siempre quise escribir, es mi declaración de amor a la literatura, a los géneros narrativos, a la fantasía, al poder de la palabra para crear realidades alternativas» (Ex Libris, 2004: 92), de ahí que la llegue a considerar su ars poetica, «el resultado de toda una vida dedicada a la literatura, como lectora, estudiante, profesora, investigadora literaria y escritora» (Ex Libris, 2004: 93). Además, no debemos olvidar que la autora vive desde hace unos cuantos años en Innsbruck, desde donde ha tratado de crear «una novela cosmopolita, europea, que no se base en modelos estadounidenses; una novela donde los personajes hablan lenguas diferentes, viven en distintos países de Europa y son conscientes de su propia tradición» (Ex Libris, 2004: 93).

Aunque El vuelo del Hipogrifo tiene alrededor de cuatrocientas cincuenta páginas, Elia Barceló siempre se ha movido muy cómodamente entre los relatos fantásticos y las novelas cortas. A esta última variante se adscribe El secreto del orfebre, en la que, a pesar de su brevedad, la autora también ensaya un particular cóctel genérico. La novela ha sido escrita sobre la plantilla de Regreso al futuro, trilogía dirigida por Robert Zemeckis cuyas entregas se estrenaron en 1985, 1989 y 1990, respectivamente. De todas maneras, el referente cinematográfico sólo es el punto de partida, ya que El secreto del orfebre es, al menos en su esquema, una novela rosa o de amor orquestada sobre la excepcionalidad de un bucle temporal; pero, en el fondo, todo eso sólo es un marco para reflexionar sobre los dos grandes 
temas que en el mundo han sido: eros y thanatos. Esta novela corta, que ha entusiasmado a Fernando Marías, también bebe de la tradición de la novela de artista, pues el personaje principal es orfebre.

En el mejor momento de su carrera profesional, el protagonista decide regresar a la ciudad de su infancia, Villasanta de la Reina, en la región de Umbría, «el país de las leyendas, según reza nuestro eslogan turístico» (Barceló, 2003b: 13), antes de partir hacia Nueva York para empezar una nueva vida. Desde el principio, parece que al protagonista no lo mueve su voluntad, sino un destino inexorable: «aquella noche en la que mis decisiones no importaban porque todas habían sido tomadas como desde fuera, desde otra instancia que supiera lo que yo ignoraba» (Barceló, 2003b: 25). Son tres los tiempos narrativos que confluyen en El secreto del orfebre: 1999, 1974 y 1952. Toda la historia la cuenta el protagonista desde Nueva York, en los últimos días de 1999. Las alusiones a 1974 corresponden a la adolescencia del personaje, cuando tuvo un affaire con una mujer soltera, Celia Sanjuán, pero la presencia del personaje en 1952 se produce gracias a un salto temporal que él no puede controlar -como tampoco podían los tripulantes del Nimitz en El final de la cuenta atrás (1980)-. El desenlace adopta la forma del happy end de Hollywood, cuando queda abierta la posibilidad de que los amantes, burlando de nuevo al destino, se encuentren en la terraza del Empire State Building, tal como ocurría en Tú y yo (1957) y, más recientemente, en Algo para recordar (1993).

Creo que es precisamente en esta práctica, la relectura y recombinación de elementos preexistentes, donde radica la fortuna del roman fusion, que, si bien no es una creación ex novo, presenta una nueva forma de heredar las tradiciones literaria y cinematográfica, reinventándolas una vez más para el lector, que queda convertido en cómplice, pues comparte con el novelista muchos de los elementos que conforman su mundo narrativo. Ahora bien, si no es una fórmula nueva, ¿,dónde están los antecedentes? Por supuesto, en la literatura hispanoamericana, sobre todo en autores como Borges, Bioy Casares, Cortázar, Fuentes o García Márquez; también en la narrativa europea, de donde proceden los términos roman fusion y slipstream. El problema, sin embargo, se plantea a la hora de rastrear la prehistoria literaria de la novela fusión en la narrativa española de la segunda mitad del siglo XX. Elia Barceló, por ejemplo, apunta sobre todo a Gonzalo Torrente Ballester, y concretamente a Don Juan (1963), La saga/fuga de J. B. (1972) y Quizá nos lleve el viento al infinito (1984), en las que el autor ferrolano combina géneros diversos, ensaya la parodia y se atreve con la ciencia-ficción y el espionaje, fórmulas y técnicas que seguirá empleando en su obra posterior, como en la intriga policíaca de La muerte del decano (1992).

Tanto Elia Barceló como Rafael Reig se han mostrado de acuerdo en reconocer la importancia de Eduardo Mendoza en la narrativa española del último 
cuarto del siglo $\mathrm{XX}$, pero ambos creen que el autor lo dio todo en su primera novela, La verdad sobre el caso Savolta (1975). Mendoza, hasta cierto punto, puede ser considerado como modelo de la novela posmoderna en España. El roman fision sólo ha podido existir tras la posmodernidad, pues supone una lectura consciente de ella y asume sus presupuestos sin necesidad de indagar en ellos. Hay algo de fusión en el tono irónico y el juego de perspectivas que predominan en $L a$ verdad sobre el caso Savolta, pero mucho más en las novelas protagonizadas por ese personaje innominado, residente habitual de un frenopático: El misterio de la cripta embrujada (1979), El laberinto de las aceitunas (1982) y La aventura del tocador de señoras (2001). En esa trilogía, Mendoza parodia el género policíaco y perfila un particular detective, con escasas luces, que se tropieza con la verdad gracias a sus equívocos y confusiones. Aunque la crítica le ha prestado poca atención, La isla inaudita (1989) es una novela de gran interés, en la que el novelista barcelonés dibuja una Venecia insólita, distópica y desconcertante, por la que se pasea un Fábregas en plena crisis de identidad. La novela merece la pena, aunque sea tan sólo para ver cómo Mendoza ha sabido desenvolverse en un escenario tan recurrente de la cultura occidental. Más relacionados con el roman fiusion se encuentran los textos de Sin noticias de Gurb (1991) y, principalmente, El último trayecto de Horacio Dos (2002), nacidos para ser publicados en la prensa, pero que no pierden interés al haber sido reunidos en sendos volúmenes, caracterizados por su intención desmitificadora: Gurb es un extraterrestre aterrizado en la Barcelona preolímpica con el cuerpo de Marta Sánchez, mientras que Horacio Dos es el comandante de un crucero espacial que prácticamente va a la deriva con un pasaje de Delincuentes, Mujeres Descarriadas y Ancianos Improvidentes.

Las relaciones que existen entre la obra de Mendoza y los autores del roman fusion aquí referidos pueden ser más o menos directas, más o menos explícitas. pero creo que las novelas de Reig -principalmente, ya que Elia Barceló no practica la parodia en su receta de fusión- y las de Mendoza están alimentadas por un mismo espíritu de desmitificación y distanciamiento con respecto a la realidad, fuente constante de incongruencias y absurdos.

Lo cierto es que prácticamente todos los novelistas con una obra lo suficientemente extensa han practicado este tipo de ejercicios o juegos literarios, aunque no de una manera sistemática y no como centro creativo de su carrera literaria. En ese sentido, podríamos referirnos a algunas novelas de Juan José Millás o Antonio Muñoz Molina, ya que ambos se han atrevido a visitar géneros como el policíaco. Recordemos, si no, Papel mojado (1983) o No mires debajo de la cama (1999), del primero. En cuanto a Muñoz Molina, podemos destacar El invierno en Lisboa (1987), donde se recrea una atmósfera propia del cine negro; Beltenebros (1989), un relato de espías; Los misterios de París (1992), un folletín publicado previamente como tal; o Plenilunio (1997), un psycho-thriller con altas dosis de reflexión. 
Durante mucho tiempo, el género policíaco en España ha estado abocado a convivir con las novelas románticas y las del oeste, que, por otra parte, siguen teniendo grandes tiradas y se han conformado con una vida alejada de las librerías, limitándose a los espacios reducidos de los quioscos, donde comparten espacio con una amplia oferta editorial. Sin embargo, hay algunos detectives literarios de producción nacional que han conseguido abandonar esa zona marginal. Aunque Ricardo Landeira ha encontrado antecedentes del detective literario en «Una antigualla de Sevilla», del duque de Rivas, lo cierto es que todo arranca de Arsène Lupin, el personaje de Poe, y, en España, de los intentos de Emilia Pardo Bazán o de las crónicas criminales de Benito Pérez Galdós, bien conocidas por Rafael Reig, que, como se ha dicho, se ha encargado de editarlas.

Los precedentes de Carlos Clot, el protagonista de Sangre a borbotones, son los personajes de la novela negra clásica, pero también los detectives de la tradición hispánica, que ya han merecido monografías como las de Colmeiro y Vázquez de Parga. En este sentido, la fusión más original dentro del género policíaco en España la logra Francisco García Pavón en los años sesenta, al crear una fórmula detectivesca de ámbito rural a partir de un modelo eminentemente urbano. La pareja protagonista de sus novelas está formada, de acuerdo con el magisterio de Conan Doyle, por un peculiar Watson, don Lotario, veterinario sin trabajo a causa de la mecanización del campo, pero propietario de un flamante seílla en el que llevaba al infalible Manuel González, alias Plinio, trasunto de Sherlock Holmes con uniforme y jefe de la Guardia Municipal de Tomelloso. Plinio protagoniza diecinueve cuentos, ocho novelas largas y cuatro novelas cortas, distribuidas en los volúmenes siguientes: Historias de Plinio (1968), El reinado de Witiza (1968), El rapto de las sabinas (1969), Las hermanas coloradas (1970), Nuevas historias de Plinio (1970), Una semana de lluvia (1971), Vendimiario de Plinio (1972), Voces en Ruidera (1973), El último sábado (1974), Otra vez domingo (1978), El hospital de los dormidos (1981) y Cuentos de amor... vagamente (1985).

Otro ilustre detective de las letras españolas es Pepe Carvalho, de ascendencia gallega pero con residencia en Barcelona. Manuel Vázquez Montalbán lo hizo nacer en Yo maté a Kennedy (1972), pero, tal como le sucedió a Plinio, también Carvalho fue reajustándose hasta quedar según lo conocemos hoy, y reapareció en La soledad del manager (1977), Los mares del Sur (1979) y Asesinato en el Comité Central (1981), entre otras muchas.

Alejadas de las de Rafael Reig están las obras de autores como Álvaro Cunqueiro y Ana María Matute, que, sin embargo, recuerdan en muchos aspectos a El vuelo del Hipogrifo, de Elia Barceló. Ése es el caso de Ana María Matute, quien, cuando volvió a publicar tras un largo silencio, sorprendió a sus lectores con los mundos míticos de Olvidado rey Gudú (1996) y Aranmanoth (2000). 
Poco importa si ha habido efectivamente influencia univoca o recíproca entre todos estos autores, lo fundamental es comprobar cómo la novelística española ha conseguido abrirse no sólo a otras literaturas o tradiciones, sino también a distintas artes y a fenómenos de nueva acuñación. Ahora hay cierto interés editorial por publicar novelas fusión, fórmula o técnica que ha ido impregnando la narrativa del último cuarto del siglo XX, lo que ha dado como resultado una radicalización, no siempre en el sentido de la parodia o de la ruptura de esquemas narrativos.

Próximos en edad -y en afinidades, y en sello editorial...- a Rafael Reig y Elia Barceló se encuentran Javier Azpeitia (Madrid, 1962) y Antonio Orejudo (Madrid, 1963), pero, si en algún momento se consolida el roman fusion como marbete para referirse a cierta novelística española del siglo XXI, será necesario incluir a otros muchos autores. Hay, con todo, una última condición que deben cumplir los autores del roman fusion: todos los que conozco han estudiado filología, proceden del ámbito académico - casi siempre universitario- y confeccionan textos en los que se deja traslucir su amor por la literatura, compartido con otras muchas artes. No hay en ellos, por último, ninguna separación entre su dedicación profesional a la investigación literaria y su labor como novelistas, como si una fuera prolongación, extensión o ampliación de la otra. «No digo más», Carlos Clot dixit. 


\section{BIBLIOGRAFÍA}

AA. VV., Las virgenes locas, ed. de Rafael Reig, Madrid, Lengua de Trapo, 1999.

Alonso, Santos, La novela española en el fin de siglo 1975-2001, Madrid, Mare Nostrum, 2003.

BARCEló, Elia, Consecuencias naturales, Madrid, Miraguano, 1994.

- La mano de Fatma, Barcelona, Alba, 2001.

- El vuelo del Hipogrifo, Toledo, Lengua de Trapo, 2002.

- El almacén de las palabras terribles, Zaragoza, Edelvives, $2003 a$.

- El secreto del orfebre, Toledo, Lengua de Trapo, 2003 b.

- La roca de Is, Barcelona, Edebé, 2003c.

- Si un día vuelves a Brasil, Barcelona, Alba, 2003d.

- Disfraces terribles, Madrid, Lengua de Trapo, 2004a.

- El contrincante, Barcelona, Minotauro, 2004b.

BARCElÓ, Elia y Alan Dean FoSTER, Premio UPC 199. Novela corta de ciencia-ficción, Barcelona, Ediciones B, 1994.

Colmeiro, José F., La novela policiaca española. Teoria e historia critica, Barcelona, Anthropos, 1994.

Dick, Philip K., Blade Runner. ¿Sueñan los androides con ovejas eléctricas? Barcelona, Planeta, 2001 [1986].

«Entrevista con Elia Barceló», Ex Libris. Revista de Poesía, Universidad de Alicante, 5 (2004), pp. 89-97.

GraCiA, Jordi (ed.), Historia y critica de la literatura española 9/1. Los nuevos nombres: 1975-2000. Primer suplemento, Barcelona, Crítica, 2000.

LANDEIRA, Ricardo, El género policíaco en la literatura española del siglo XIX, Alicante, Universidad de Alicante, 2001.

LANGA PIZARRO, Mar, Del franquismo a la posmodernidad: la novela española (1975-1999), Alicante, Universidad de Alicante, 2000.

PÉrez Galdós, Benito, El crimen de la calle Fuencarral. El crimen del cura Galeote, ed. de Rafael Reig, Toledo, Lengua de Trapo, 2002.

Pozuelo Yvancos, José María, Ventanas de la ficción. Narrativa hispánica, siglos XX y XXI, Barcelona, Península, 2003.

ReIG, Rafael, Esa oscura gente, Madrid, Exadra, 1990.

- Marilyn (autobiografia apócrifa), Gijón, Júcar, 1992.

- La fórmula Omega. Una de pensar, Madrid, Lengua de Trapo, 1998.

- Sangre a borbotones, Toledo, Lengua de Trapo, 2002.

- Guapa de cara, Madrid, Lengua de Trapo, 2004.

ROAS, David (ed.), Teorías de lo fantástico, Madrid, Arco, 2001. 
SanZ Villanueva, Santos (ed.), Historia y crítica de la literatura española $8 / 1$. Época contemporánea: 1939-1975. Primer suplemento, Barcelona, Crítica, 1999.

SobejANO, Gonzalo, Novela española contemporánea 1940-1995, Madrid, Mare Nostrum, 2003.

SOldevila Durante, Ignacio, Historia de la literatura española actual. II. La novela desde 1936, Madrid, Alhambra, 1980.

Telotte, J. P., El cine de ciencia ficción, Cambridge, Cambridge University Press, 2002.

VAlLS, Fernando, La realidad inventada. Análisis crítico de la novela española actual, Barcelona, Crítica, 2003.

VÁZQUez DE PARGA, Salvador, Los mitos de la novela criminal. Historia y leyenda de toda a literatura de criminales y detectives desde Poe hasta la actualidad, Barcelona, Planeta, 1981.

- La novela policiaca en España, Barcelona, Ronsel, 1993. 